\title{
Journey to a Sustainable World
}

\author{
Robert C. Pfahl \\ Motorola Advanced Technology Center \\ Motorola Labs \\ 1301 East Algonquin Road \\ Room 1014 \\ Schaumburg, IL 60196 \\ bob.pfahl@motorola.com
}

\begin{abstract}
Environmental attributes are becoming a factor of growing importance at all stages of an electronic products life cycle from design to end-of-life. The Journey to a Sustainable World is Motorola's theme for its environmental programs. This paper highlights the activities of Motorola's Environmental Technology Programs, focusing on our product goals and our activities to achieve these goals. Additional information on Motorola's goals, programs and achievements on our Journey to a Sustainable World are available at http://www.mot.com/EHS/
\end{abstract}

\section{Introduction}

To remain competitive, the electronics industry must be prepared to comply with future international environmental policies and must develop environmentally conscious production techniques and products to meet global market equirements. The costs associated with environmental compliance and waste product disposal are soaring in North America. European and Japanese environmental regulations focus on products and include product packaging, "take-back" regulations in Germany, as well as electronics recycling and hazardous waste regulations in Japan.

Societal concerns such as sustainability, global warming, and pollution are the environmental drivers for change. They influence changes in public policy and in purchasing behavior. Industrial customers are asking suppliers either to eliminate certain materials or to provide certain environmental attributes. Consumer electronics are beginning to be marketed based on their environmental attributes. Consumers throughout the world expect to see the Energy Star on their computer purchases and energy efficiency on their refrigerators. In Europe and the United States consumers are purchasing washing machines based on water usage; in Japan the customer is observing that certain products do not contain $\mathrm{Pb}$ solders or that they are highly recyclable.

While the drivers are similar at a global level, there are strong regional differences, as summarized in Table1.

The regional differences in drivers have influenced both the focus of the regional programs as well as the $\mathrm{R} \& \mathrm{D}$ and key programs in each region. However, there is general global agreement on the attributes of environmentally preferred products:

- Minimize Use of Energy

- Minimize Use of Matter

- Contain Non-Hazardous Materials

- Are Highly Recyclable

Motorola's activities to address these four attributes are established by the following seven goals:

- All manufacturing sites ISO 14001 certified (Achieved in 2000)

- Design our products to be highly recyclable

- Reduce the use of hazardous materials

- Reduce energy use in our products

- Increase the use of recycled materials in our products

- Minimize the ratio of packaging material to product volume

- Label all plastic parts weighting greater than 4 grams to aid future recycling.

The first changes in industries' attitudes to the environment occurred in the 70's with the enactment of many of the environmental regulations we take for granted today. Much of the work today has progressed beyond the regulation of emissions and has started to look at sustainability and sustainable use of resources. Sustainability has been defined as meeting the needs of the present without compromising the ability of future generations to meet their own needs. Future generations'ability to survive can be impeded in many 
forms. For example, the use and loss of materials from dispersion into the environment and collapse of the ecosystem from species loss or from hazardous materials release are two possible outcomes if some of today's activities remain unchanged.
Motorola's Journey to a Sustainable World is the inception of redesigning Motorola's products to reduce their impact on the environment. The major areas of interest in this set of activities are hazardous material reduction, increasing the reuse of materials, and managing

Table 1. Driver Differences by Region

\begin{tabular}{|c|c|c|c|l||}
\hline REGION & DRIVER & FOCUS & R\&D & KEY PROGRAMS \\
\hline \hline $\begin{array}{c}\text { States } \\
\text { Europe }\end{array}$ & $\begin{array}{c}\text { Regulation } \\
\text { Regulation }\end{array}$ & Factory & $\begin{array}{c}\text { Manufacturing } \\
\text { Focused }\end{array}$ & $\begin{array}{l}\text { CFC Elimination } \\
\text { VOC Reduction } \\
\text { Lead Reduction }\end{array}$ \\
\hline Japan & $\begin{array}{c}\text { Government } \\
\text { Industry }\end{array}$ & Market & Product & $\begin{array}{l}\text { Design for Environment } \\
\text { Life Cycle Analysis } \\
\text { Material Flow Analysis }\end{array}$ \\
\hline \hline
\end{tabular}

environmental performance. These are first steps, but important ones. Much of the difficulty with managing environmental performance is that measures of success often are not quantified. While understanding intuitively where work is needed, measures of progress and analytical decision tools are just becoming available.

One area receiving considerable attention is lead $(\mathrm{Pb})$ replacement in solder. At the same time, we have developed several tools to measure improvement in the environmental performance of our products as we eliminate lead and improve product recyclability. The following sections highlight our materials $R \& D$ to replace $\mathrm{Pb}$, describe the environmental design tools that we have developed, and show in a case study how we apply materials $R \& D$ and environmental tools to enhance environmental performance of to our products.

\section{Motorola's Pb Replacement R\&D}

Motorola has conducted almost a decade of research to find alternative solders to replace tin lead solders. A survey article of our research recently was presented in Japan, ${ }^{1}$ and the details will not be repeated. The results of this review showed that $\mathrm{Sn}-4.7 \mathrm{Ag}-1.7 \mathrm{Cu}$ and $\mathrm{Sn}-0.7 \mathrm{Cu}$ have comparable properties to near eutectic $\mathrm{Sn}-\mathrm{Pb}$ and can be used as substitutes for Pb-bearing solders for many applications. The increased process temperature of $\mathrm{Pb}$ free solder alloys affects the choice of the packaging materials and flux. These restrictions must be considered when selecting the $\mathrm{Pb}$-free alloy. $\mathrm{Sn}-\mathrm{Ag}$ and $\mathrm{Sn}-\mathrm{Cu}$ are recommended for lead finish, whereas $\mathrm{Sn}-\mathrm{Cu}$ is recommended for wave soldering and flip chip bumping and $\mathrm{Sn}-\mathrm{Ag}-\mathrm{Cu}$ is recommended for surface mount assembly. Motorola, through its leadership in the NEMI $\mathrm{Pb}$-free solder project has worked to create a standard alternative to eutectic tin-lead solder.

\section{Design Tools}

\subsection{The Green Design Advisor: A DfE Tool}

Engineering is a profession of disciplined measurement and calculation. Such rigor needs to be applied to the field of Environmental Technology. Although there are a number of potential metrics that could be used to measure environmental performance, many are either impractical or measure effects so distant from product design decisions that they are not useful. Motorola compiled a list of potential metrics and eliminated those that were not quantitative measures of product performance or were not related directly to product design features. This rather short list of measures was then incorporated into a design tool called the Green Design Advisor (GDA). The GDA is now the standard design tool for Design for Environment within Motorola.

The Green Design Advisor is used to assess the environmental impact of a product for both the reduction in hazardous materials content and recyclability. The results of the GDA analysis provide the engineer an end of life value, the time for disassembly and the percentage of material going to a recycler. All of this information can be used to educate the consumer to the real end of life value and used by an engineer to improve that value until it matches the perceived value of the product.

DfE requires the simultaneous optimization of all the environmental criteria (e.g., recyclability, resource use, 
energy) over the full life of a product. Otherwise, customers or other stakeholders may not accept a claim of improvement. Many of the tradeoffs among environmental goals are unfamiliar to the engineer and the implications of the tradeoffs are not clear. The Green Design Advisor (GDA) was developed to bring together multiple scoring criteria that had different scales and magnitudes and give designers a consolidated score. To perform this task multiattribute analysis is employed. The eight criteria evaluated are: energy, mass, recycled material content, recyclability, number of materials, toxicity, disassembly time, and commodity value.

The result is a single score reflecting the preferences and values of the customer in a given design exercise. The final score is not as important, however, as is the impetus that the score gives to the design engineer to explore the source of the score. The charts and tables generated in the DfE process allow the tracing of high scores to specific materials or processes, and thus influence the designer, for example, to shift to a material with less environmental impact. The results of the analysis are normally presented in the form of an Inverse Spider Chart, where the objective is to minimize environmental impact by making the area of the chart as small as possible for a given design. An example chart is presented in the Case Study in Section 4: Case Study.

While each of the eight criteria are important, most of the effort in developing the GDA went into the application of a recycling modeling simulation developed with the University of Erlangen. The function of the algorithm is to aid the designer to improve the recyclability of his products.

From a recycler's viewpoint, this means that the product is easily disassembled, and that all the parts have a high value as recycled material. This goal presents a challenge to the designer, for the last thing they want is for a product to fall apart. At the same time, the designer also wants to use the least costly material that performs the function of the part. Therefore, we have two areas to simulate, the time for disassembly and the value of the materials. To minimize the disassembly time, connections need to be quickly taken apart with the best time being no disassembly at all. But, if the two parts held together by that connection are not compatible, in other words, they are contaminants in each other's recycling box, the combined parts have no value. The algorithm simulates the disassembly of a product by the recycler. The algorithm searches for the best combination of disassembly and material value, trying to find a recycling box for each of the components or clumps of components. A recycling box is a numerical description of the allowable purity and contaminants for each of the material categories that a recycler accepts.

The algorithm represents the product using parts and connections. The model displayed on the screen as the connectivity graph is shown in Figure 1. Ovals represent parts and circles depict connections. The mass and the material composition define each part. The material composition is the amount, by mass or percent, of each of the materials in the part. These are used with the environmental impact data in the materials database to determine the environmental impact of the product as a whole.

\section{Figure 1.- Parts and Connectivity Model}

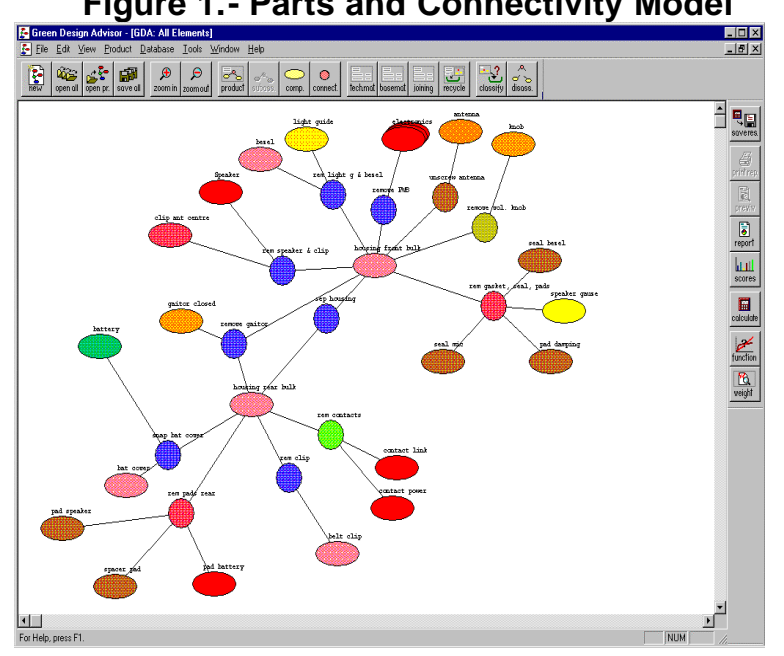

The GDA is now in its third generation within Motorola. Designers are using the GDA as the standard for evaluating environmental performance. This tool will drive Motorola products to more environmentally preferred materials and enhance the ability of recyclers to recover materials from Motorola products.

\subsection{Life Cycle Assessment Tools}

In addition to using the Green Design Advisor as a DfE tool, Motorola Labs has found that performing joint LCA studies with our customers allows for the joint measurement of environmental attributes over the entire life cycle. These LCA studies can then be used to jointly identify opportunities for environmentally preferred products or systems. Motorola uses commercial tools for performing its life LCA studies. In one example, the energy use was studied during several phases of the life cycle of a cellular telephone. While energy use during manufacturing is limited and mainly driven by the production of components, the main energy use occurs during the use phase, with the charger in stand-by dominating.

The energy consumption during operation of the phone and recharging of batteries was investigated and the charger for the product has been redesigned to minimize the stand-by energy use. This energy use is of particular interest since it has been reported by the European 
Commission that electricity is responsible for $30 \%$ of total $\mathrm{CO}_{2}$ emissions, and that stand-by losses of consumer equipment may account for $5-10 \%$ of household energy use.

\section{Case Study}

Motorola produced an ecologically improved mobile phone using its Green Design Advisor tool to identify areas for improvement. The Motorola V2288 Environmental Limited Edition, Figure 2, is made with a housing of recycled plastic, an energy-efficient charger, a lead-free solder, and a bromiumfree PWB. The phone was developed to gage the interest of consumers.

Figure 2. V2288 Environmental Limited Edition

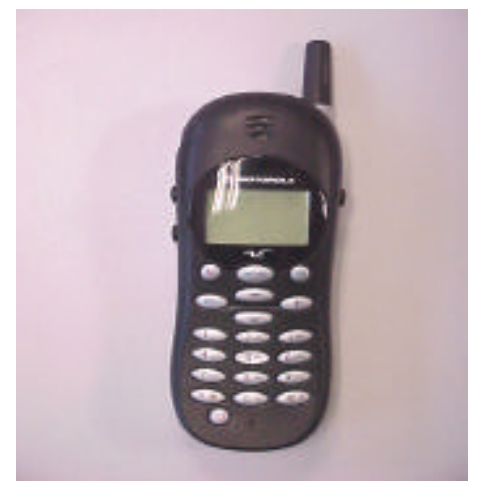

The housing of the environmental friendly phone is made of plastic recyclate. For this application, compact discs (CD's) were taken back and reprocessed. '2 The same quality and functionality as for virgin plastic housings is ensured. Significant savings in resources and energy use can thus be achieved. The phone uses a Printed Wiring Board (PWB) without any brominated flame-retardants, ${ }^{3}$ while still assuring current safety levels. Brominated flame-retardants are suspected to be a cause for Dioxin emissions at incineration. The product is also assembled using a lead $(\mathrm{Pb})$-free solder to mount the components. The potential danger of $\mathrm{Pb}$ leaching in landfill and contaminating ground water can be minimized. The GDA Spider Chart in Figure 3 quantifies the improvement that was made in the Environmental Limited Edition phone in toxicity by reducing the use of $\mathrm{Pb}$ and bromine based flame retardant. It also shows the improvement in energy use through the re-designed charger and increased recycled contents by using recycled plastic.
Figure 3. GDA Improvement of V2288 Environmental Limited Edition

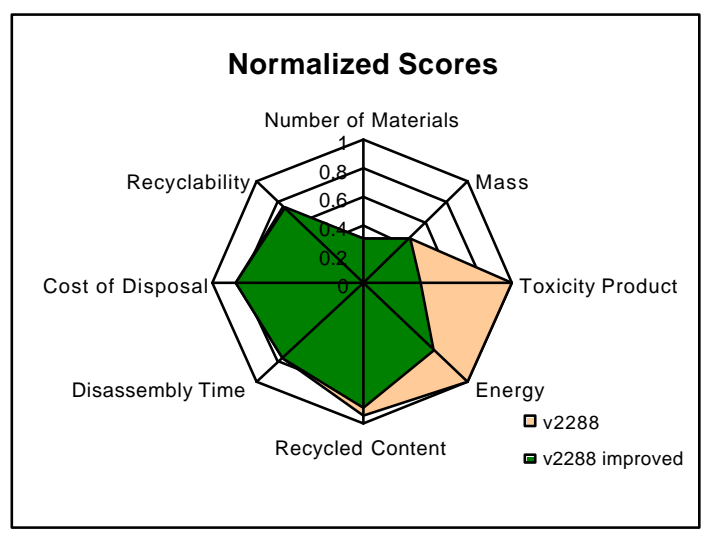

\section{Concluding Remarks}

Motorola's Personal Communications Sector and Swisscom displayed this ecologically improved mobile phone prototype based on the standard v2288 phone at Orbit/Comdex show in Switzerland in September 2000. The Motorola V2288 operates in GSM 900/1800 dual band technology with integrated FM radio, SMS messaging, WAB micro browser, and features a large easy to read display. The ecologically improved prototype is made with a lead-free solder, a bromium-free printed wiring board, a housing of recycled plastic as well as an energy-efficient charger. The product was developed in order to conduct further research and tests and gage the interest of customers and consumers in an ecologically improved mobile phone.

The electronics industry is a dynamic industry noted for its short product life cycles. These short life cycles serve the environment well in permitting the rapid introduction of environmentally preferred materials to products; however, the industry's current short life cycles with limited functional end-of-life value is not consistent with sustainability. Additional $R \& D$ directed at sustainability is critical on our Journey to a Sustainable World.

\section{Acknowledgments}

The author would like to acknowledge contributions of colleagues at Motorola including William Hoffman, Jim Arnold, Markus Stutz, Siegfried Pongratz, and Daryl Frear. 


\section{References}

1. Frear D, Arnold J, Pfahl RC, "Environmentally Preferred Packaging: Pb-Free Solder" 2001 ICEP (International Conference on Electronic Packaging)

2. Doreen S, Stutz M, JVC "Feasibility Study for Recycling of JVC CDs for use in Manufacturing Motorola Plastic

Housings" To be published Eco-Design 2001 Tokyo, Japan

3. Stutz M, Tungare A, Riess M, "Combustion of Halogen-Free Printed Wiring Boards and Analysis of Thermal Degradation Products " Electronic Goes Green 2000 Conference Berlin, Germany 